Journal of Social Sciences 4 (2): 146-157, 2008

ISSN 1549-3652

(C) 2008 Science Publications

\title{
A Review on Factors Impinges Computer Usage in Education
}

\author{
Naresh Kumar, Raduan Che Rose and Jeffrey Lawrence D'Silva \\ Graduate School of Management, Universiti Putra Malaysia, Malaysia
}

\begin{abstract}
The growing body of literature associated with educational computer use had examined numerous variables and interrelationships in order to gain a better understanding of computer beliefs and use of computers within education. Teachers' computer acceptance is an important factor to the successful use of computers in education. Thus it is significant to draw attention to the factors affecting teachers' computer use and its implications to teachers' professional development strategies. This article would be useful for future researchers who are seeking directions to further examine the determinants of computer technology acceptance and its utilization based on the technology acceptance model.
\end{abstract}

Key words: Usage of computer, acceptance model, education, teacher, utilization, development strategies

\section{TEACHERS' USAGE OF COMPUTER}

Sherry et $a l^{[1]}$ and Loveless $^{[2]}$ contended that teachers were unprepared for using computers in their teaching except in the most basic forms of instruction, allowing students to use it as a reward or for drill and practice type activities. Loveless placed the blame on the characteristics of teachers' and their work. In general, teachers use computers not just to teach but for a myriad of different reasons, though they may deem to be job-related ${ }^{[3]}$. Teachers since beginning are not only teaching but involved in a number of clerical works and nowadays the clerical aspect of teaching has seen a steady increase, as we are well informed through the countless articles published in the newspapers about teachers and teaching ${ }^{[4]}$. It is not surprising that Gibbons and Fairweather ${ }^{[3]}$ found in their study that the Actual Usage of Computer (AUC) by teachers do not confine to teaching purposes but is also for other jobrelated reasons such as administration work. The administration here would include the many obligatory works that a teacher needs to be engaged in for the well-flow of the administration of the whole unit of the teaching process. This would include; the keying in of students' personal data, students' work progress, teachers' personal data, setting of examination papers, preparation of mark scheme, preparation of spread sheets and students' progress reports and other student/teacher related tasks ${ }^{[5]}$.

Perhaps, it is erroneous to label teaching as a process that involves merely teaching in the classroom.
The thorough progression involves the process of preparation, at the very beginning, to the evaluation, at the very end ${ }^{[6]}$. The actual teaching is but a minor part of the whole teaching process but that too needs prior preparations that will need the use of computers ${ }^{[7]}$. Over and above, the Actual Usage of Computer (AUC) in classroom teaching is only when a teacher wishes to use the computer during the lesson to present an idea in a different style. More time is spent on the computer to prepare materials and administer the smooth flow of the organization of the school and ensure the safe-keepings of data and information ${ }^{[7]}$.

Further studies reveal the fact that the AUC by teachers involve other job-related tasks such as the use of computers for the preparation of school magazines, newsletters, notices and bulletins, programmes books for the wide array of activities run by schools at various levels such as drama, poem-recital, elocution, choir, scrabble, oratory and debate competitions ${ }^{[5]}$. These again point towards the fact that teachers use computers not just to teach in the classroom but also for administration purposes. In addition, in relation to administrative matters, Kellenberger and Hendricks ${ }^{[8]}$ state that a teacher generally uses a computer for preparing examination papers, syllabus, data and statistics, notes for presentation, typing clerical matters and as a mode of communication with parents, students and colleagues.

The use of computers by teachers in schools does not confine to the AUC in the classroom because teachers

Corresponding Author: Naresh Kumar, Graduate School of Management, Universiti Putra Malaysia, Malaysia Tel: 603-8946 7433 Fax: 603-8943 4019 
are a group of professional staff who are involved in the preparation and running of many activities, job-related and non job-related as well ${ }^{[3]}$. Many teachers resort to the computers, especially the internet, to look for information that may not be job-related. Gibbons and Fairweather ${ }^{[3]}$ further added that owing to the fact that it is the era of advanced technology and time of information technology, it would be ridiculous to have teachers confine to using computers for merely teaching. Most teachers, in fact more than $90 \%$ of them use the computers for personal reasons. Martin and Ofori-Attah ${ }^{[9]}$ found that the AUC by teachers could be divided into three components namely, for teaching purposes, administration purposes and personal purposes. The personal use of computers as identified by Martin and Ofori-Attah ${ }^{[9]}$ would include, preparation of thesis and materials for revision books, writing letters and reports that are non job-related and in the completion of personal assignments.

The internet plays a significant influence in the use of computers by civilians including teachers ${ }^{[3]}$. Teachers fill their free time, at times, surfing the net; reading the newspaper, chatting or just browsing around the many web-sites to enhance knowledge and acquire the latest information. Some are found to use the computer to purchase items, reserve air tickets and even play computer games to release stress ${ }^{[10]}$. The internet has paved way for a hassle free marketing system. This has made it convenient for shoppers to shop without much fuss and fury. Needless to say, making payments and clearing bills easy ${ }^{[3]}$. On top of it, in terms of personal needs, a teacher quite often use the computer to enhance knowledge on computer hardware and software, typing, browsing the net for information, listening to music and watching movies and enriching vocabulary $^{[8]}$.

Brunner et $a .^{[5]}$, avowed the primary use of computers by teachers is for administrative purposes. They state that the preparation of job-related materials takes a considerable toll on the teachers' anatomy and that the computer has now provided an easy way to solve this tedious affair. With the birth of the computer, the selected materials could be prepared once and than tailored to be used many times. Besides, Kellenberger and Hendricks ${ }^{[8]}$ further added that the type of work that a particular teacher uses a computer for teaching and learning is to introduce a topic in a particular subject, demonstration of a process and procedures on a particular topic, downloading information and graphic materials, typing worksheets, using language games and using electronic evaluation to test students' ability. On the other hand, it could not be discounted that teachers are mortal beings with human instincts to use the computer to ease their personal burdens such as to prepare personal materials which are not related to teaching and learning ${ }^{[9]}$. Many teachers attend classes to up-grade they status and some write books. Personal letters of complaints and other materials that require the work of the antiquated typewriter has now been replaced by the efficient computer. Thus, as shown by literature, the computer is more efficient, reliable and ease-of-use and more people, especially teachers are resorting to it regardless of whether it is job-related task or non job-related task ${ }^{[7]}$.

From the literature search, it could be easily deduced that teachers use computer for three main purposes. Firstly, the AUC by teachers is for teaching and learning. They use the computer to impart knowledge in the classroom, create variety, conduct activities, easily deliver their wordy explanations and instill interest in the lesson they are teaching ${ }^{[3]}$. The computer gives teachers the confidence in the classroom as they are not looked down by their students as obsolete and old fashioned. They prove to the contemporary generation that they too know modern technology and are not left behind time ${ }^{[7]}$.

Secondly, the AUC among teachers is to ease their administrative works. Many data and information of students, their parents' as well as themselves need to be fed into the computer. Apart from that the copious activities that are run by the school need the assistance of the computer to fulfill the tasks. The computer has helped to make matters easy and up-to-date ${ }^{[9]}$. Information stored in the computer may be easily retrieved and with slight alterations, used again for another project. Hence teachers' resort to the computer to complete their job-related tasks and retrieve it in future and with a few adjustments the job is ready for the following year's lessons ${ }^{[9]}$.

Thirdly, teachers resort to the computer for personal use. Their free time is fruitfully occupied with the advent of the computer that has provided the proper avenue to fill they time beneficially ${ }^{[3,6]}$. Teachers are a group of educated people. They spend most of their time reading and writing ${ }^{[6]}$. Consequently, they have easily adapted themselves to the computer that provides almost everything through a click of the mouse ${ }^{[9]}$. It has been proven to be a convenient tool enabling the reach to knowledge of high value and so teachers resort to them without hesitation.

\section{THEORETICAL MODELS TO EXPLAIN IT USAGE}

According to Stefl-Mabry ${ }^{[11]}$, the understanding on the dynamics of human decision making in the 
perspective of accepting or resisting technology is being derived from the field of Management Information System (MIS). User acceptance as defined by Dillon and Morris ${ }^{[12]}$ is the willingness within a user group to employ information technology to the tasks it is designed to support. There are number of models in the IT literature that has evolved over the years propose to explain human dimension associated with IT acceptance and subsequent use. Despite the electrifying advances in hardware and software capabilities, the problem of underutilized IT remains ${ }^{[13]}$. The tendency to focus more on technical aspects and systems while neglecting the behavioral problems associated with individual users, are largely responsible for IT failure ${ }^{[14]}$. Kukafka et al..$^{[13]}$ explained that if we are to understand better how human behavior is associated with IT system failure, then it is important that we draw on what has been learned from behavioral sciences about humans and their interactions with technology. One basic tenet of behavioral sciences is that a theoretically guided approach can favorably influence factors associated with IT usage. A behavioral approach is important for understanding implementation to promote IT use since it implies using organized activities to intervene in the process of human development and change.

Behavioral intention theory: The intention-based models emphasize the behavioral intentions of individual, such as attitudes, social influences and facilitating conditions to predict information technology use. The Theory of Reasoned Action (TRA) and its later iteration, the Theory of Planned Behavior (TPB), are known as one such prominent intention-based model ${ }^{[15]}$. The TRA is a general theory of human behavior $^{[15]}$ and it defines relationships among beliefs, attitudes, norms, intentions and behavior. In TRA, it explains that intention to use a particular technology is based on two factors that reflect personal interests and social influence. The personal factor, commonly known as the attitude toward behavior, is the individual's evaluation of adopting the technology. On the other hand, the social factor encompasses perceptions of individuals' of what they believe others expect them to do and the strength of their motivation to comply with those expectations ${ }^{[13]}$. In other words, according to TRA, a person's performance of a specified behavior is determined by his or her Behavioral Intention (BI) to perform the behavior and $\mathrm{BI}$ is jointly determined by the person's attitude and subjective norm concerning the behavior.

An extension of TRA is the TPB with the addition of a construct called perceived behavioral control and this construct is deemed to enlighten for factors beyond the individual's control that could affect the individual's intention and behavior ${ }^{[15]}$. Precisely, TPB explains that an individual's behavior is subjected to the behavioral intention of the person and it is jointly influenced by attitude, subjective norms and perceived behavioral control. According to Ajzen and Madden ${ }^{[16]}$, attitude is the evaluation of the performance effect of a particular behavior, subjective norms are perceptions of individuals based on other people's opinions on whether the particular behavior should be performed and perceived behavior control are the perceptions of individuals on the essential resources necessary for performing a behavior. In conclusion, according to TPB, three critical predictors to explain an individual's intentions towards adopting new technology are his or her perceptions that the innovative is (1) personally desirable, (2) supported by social norms and (3) feasible.

The Technology Acceptance Model (TAM), an adaptation of TRA, is a parsimonious, theoretically and empirically justified model aimed at explaining the usage of information systems ${ }^{[17]}$. It states that behavior is driven by the intention to use a system, which in turn is driven by the user's attitude and perceptions of normative influences ${ }^{[18]}$. The model posits that Perceived Usefulness (PU) and Perceived Ease Of Use (PEOU) are the primary determinants of system use. Perceived use is defined as the prospective user's subjective probability that using a specific application system will increase his or her job performance within an organizational context, while perceived ease of use is referred to the degree to which the prospective user expects the target system to be free of effort ${ }^{19]}$.

According to TAM, the two factors of PU and PEOU will have a significant impact of a user's attitude toward using the system, defined as feelings of favorableness or unfavorableness toward the system ${ }^{[11]}$. Behavioral intention to use the system are modeled as a function of attitude and perceived usefulness. Research has consistently shown that behavioral intention is the strongest predictor of actual use $\mathrm{e}^{[17,19,20]}$. Over the years several empirical studies were carried out on TAM and the findings revealed that perceived usefulness, but not perceived use, was positively related to behavioral intention to use an information system or information technology ${ }^{[21]}$. However, there were studies that showed both perceived usefulness and perceived ease of use are positively related to the behavioral intention to use and the actual usage of information system or information technology ${ }^{[22]}$. Consequently, Shih ${ }^{[23]}$ concluded that perceived usefulness is the major determinant of individual intentions to use an information technology, while perceived ease of use is a secondary determinant. 
Extended technology acceptance model: From its original model that was developed by Davis ${ }^{[18]}$, the technology acceptance model has evolved over time ${ }^{[24]}$. Many studies have replicated, extended and used the technology acceptance model to examine the convergence and divergence of TAM relationships across different settings to make better claims on the model $^{[25]}$. In the various applications of the TAM, a number of studies have also suggested various ways of broadening the overall applicability of the TAM ${ }^{[26-29]}$. In the field of education, extending on the technology acceptance model, $\mathrm{Hu}$, Clark and $\mathrm{Ma}^{[30]}$ derived a model that used the constructs of perceived ease of use, perceived usefulness, subjective norm, self-efficacy, compatibility and job relevance but excluded attitude to investigate on usage of computers by teachers. According to the model, a teacher's decision to use a technology is linked with the technology usefulness, ease of use, computer self-efficacy, job relevance, compatibility and subjective norm.

The model states that all others being equal, a teacher is likely to consider using the computer technology if it is useful and when it is easy to use. Hence they proposed that the degree to which a teacher considers computer technology to be useful and be easy to use have a positive effect in the AUC. The findings of the model also revealed that perceived usefulness was the most determinant of teachers' usage throughout the investigation. It had a positive effect on AUC and the effect appeared to have strengthened with user experience of computer technology. Computer selfefficacy too had an effect on technology usage decisions. Previous self-efficacy theory ${ }^{[31]}$ had shown that computer self-efficacy, which is referred to as an individual's judgment of his or her ability to use a computer, might influence an individual's perception of AUC. In line with previous findings, this model postulates a positive effect of computer self-efficacy on AUC. The findings of this model supported computer self-efficacy's effect on user acceptance and usage of computer technology. However, the effect of computer self-efficacy on individual's usage decisions decreases with user's experience as the course of training intensifies $^{[30]}$.

The model also emphasizes the importance of the construct of job relevance towards AUC. It is commonly known that teachers have considerable autonomy in teaching that includes choice of teaching material, delivery methods and technology use. In this vein, the assessment of a technology's relevance to routine classroom activities is important ${ }^{[30]}$. Hence, the model suggests that the extent to which computer technology is relevant to a teacher's job has a positive effect on his or her AUC. The findings of the model had identified a significant and prominent core influence path from job relevance to perceived usefulness and then AUC. Hu et al. ${ }^{[30]}$ model too implies that computer compatibility can affect a teacher's acceptance decision on using computer technology. They explained that from a system perspective, being compatible with both the hardware and software is pertinent and may affect a teacher's decision to accept a technology, especially when taking into account their limited technology training or experience. Therefore, they emphasized that the degree to which computer technology is considered by a teacher to be compatible to the computer hardware and software of routine use at school has a positive effect on AUC.

With regards to the construct of subjective norm, the model states that a teacher may be motivated to accept a technology and enhance on the AUC in order to comply with important referents' opinions or a community norm and such effects are encompassed in the theory of planned behavior. It further elaborates that since schools are part of a social system, schoolteachers would have strong psychological attachments with their colleagues and the community in it. Among the factors that might contribute to these attachments are the nonprofit nature of the schools, less direct competition among peers, personal commitment to education, longterm career pursuit and the relatively closed-loop community ${ }^{[30]}$. Thus, teachers may decide to use computer technology partially because their colleagues and school administrators are in favor of the decision. This brings forth to the following notion, that is, a teacher's subjective norm concerning usage of technology has a positive effect on AUC. However, it was interesting to note in the model, that there was a shift in subjective norm that appears to be a significant driver for initial acceptance but then diminishes in importance as individuals become experienced with computer technology ${ }^{[30]}$. Besides, in other extended TAM study, Shih ${ }^{[23]}$ combined the technology acceptance model and the information behavior model to develop an extended TAM for internet use. The theoretical model was tested via a questionnaire survey of 203 office staff. In the study, it was identified that the factors that contribute towards usage of information technology were consistent with the propositions of TAM and more importantly, the study found that the influence of relevance and attitude was pertinent towards usage of information technology.

Innovation diffusion theory: According to Kukafka et $a l .{ }^{[13]}$, the Innovation Diffusion Theory (IDT) is the second line of behavioral research that is useful to 
understand information technology use. Rogers ${ }^{[32]}$ explained that innovation is an idea perceived, as new by the individual and diffusion is the process by which an innovation is spread over time in a sequence among the members of a social system through certain channels. Rogers ${ }^{[32]}$ further adds that innovation is not adopted at the same time by all the individuals in a social system. Hence, individuals are classified into adopter categories on the basis of their innovativeness. This dimension of innovativeness is partitioned into five adopter categories of (1) innovators, (2) early adopters, (3) early majority, (4) late majority and (5) laggards.

Besides the characteristics of adopters, differences in innovation attributes too help to explain the rate of adoption. These attributes are relative advantage, compatibility, complexity, trialability and observability. Kukafka et al.$^{[13]}$ interpreted these attributes as follows: (1) relative advantage is the degree to which an innovation is perceived as better than the idea it supersedes, (2) compatibility is the degree to which an innovation is perceived as being consistent with existing values, past experiences and needs of potential adopters, (3) complexity is the degree to which an innovation is perceived as difficult to understand and use, (4) trialability is the degree to which an innovation may be experimented with on a limited basis and (5) observability is the degree to which the results of an innovation are visible to others.

In relation to the above, in terms of computer technology, its' relative advantage is the degree to which teachers perceive it as being better compared to the present method. The compatibility of computer technology is the extent to which it is perceived as being consistent with the existing values, past experiences and needs of teachers. The degree to which teachers perceive computer technology to be difficult to understand and use is related to characteristics of complexity. Trialability is the degree to which computer technology may be experimented with on a limited basis before teachers make a decision to adopt. Finally, the degree to which the results of an innovation are visible to others is associated with the attribute of observability.

Social-cognitive theory: The Social-Cognitive Theory (SGT) is the third line of research that provides information to explain patterns of ICT usage, with a central theoretical construct known as reciprocal determinism ${ }^{[13]}$. Reciprocal determinism is the interaction of person, behavior and environment to determine behavior and learning. Based on the socialcogniitve theory, the constructs that influence usage of
Table 1: Models to explain information technology usage

\begin{tabular}{ll}
\hline Model & Variables \\
\hline Technology acceptance model $^{[19]}$ & Perceived usefulness \\
& Perceived ease of use \\
& Attitude \\
Extended technology acceptance model $^{[30]}$ & Perceived usefulness \\
& Perceived ease of use \\
& Self-efficacy \\
& Job relevance \\
& Subjective norm \\
& Computer compatibility \\
& Perceived usefulness \\
Innovation diffusion theory ${ }^{[32]}$ & Perceived ease of use \\
& Compatibility \\
& Triability \\
& Observability \\
Social-cognitive theory & Self-efficacy \\
& Person \\
& Behavior \\
& Environment \\
\hline
\end{tabular}

information technology are the environment (factors physically external to the person), situation (person's perception of the environment), self-efficacy (person's confidence in performing a task), outcome expectations (the value that a person places on a task), reciprocal determinism (the dynamic interaction of the person with the environment in which the behavior occurs) and reinforcements. Moreover, according to Kukakfa et $a l^{[13]}$, in the social-cognitive theory, selfefficacy is deemed as the most important construct to IT usage since it fosters both the adoption of new behavior and it maintenance. The influence of selfefficacy is pertinent as it has the power not only to achieve a person's successful interactions with technology but also as an agent of reinforcement.

Summary of theoretical models to explain information technology usage: Based on the literature review, numerous information technology models are postulated in an attempt to explain the usage of information technology. Each model has its main components and strength in determining the consequences. In general, the prominent models that can be used to explain IT usage are the technology acceptance model, the extended TAM, innovation diffusion theory and the social-cognitive theory. The constructs contained in each of these models are shown in Table 1.

\section{FACTORS AFFECTING TEACHERS USAGE OF COMPUTERS}

There have been many studies that were implemented to identify factors that facilitate or prohibit computer usage among teachers ${ }^{[33]}$. Based on 
the prominent models of IT usage, there are a number of personal, behavioral and environmental factors that influence a teacher's use of technology and this could be classified as the technology acceptance constructs ${ }^{[30]}$. Personal and behavioral factors that have been identified frequently are attitude, perceived ease of use, perceived usefulness, self-efficacy and computer compatibility. On the other hand, the environmental factors of subjective norm and job relevance too may contribute to or inhibit teachers' performance in using computers $^{[34]}$.

Attitude: Attitudes are defined as an evaluative disposition based upon cognitions, affective reactions, behavioral intentions and past behaviors and it describes general individual feelings of favor or disfavor toward a specific behavior ${ }^{[23,27]}$. There have been a number of studies that indicate attitude has strong implications on $\mathrm{AUC}^{[35]}$. Woodrow ${ }^{[36]}$ showed that a positive computer attitude is a necessary prerequisite and an integral part of computer literacy and that attitudes influence not only whether one accepts computers, but also such future behaviors as using computers as a professional tool and integrating computer applications into the classroom. Teachers' positive attitudes towards computers are recognized as a necessary condition for effective use of computers in schools. Becker ${ }^{[37]}$ explained that teachers' attitude toward technology must be favorable in order for professional development programs to succeed with any hope of long-lasting effects on the standards of student accomplishment. Besides, according to Kontos ${ }^{[38]}$ successful teachers need to be knowledgeable and skilled in the application of new technologies in order to extend teaching effectiveness besides enhancing positive attitudes.

Other studies have tried to determine the factors that contribute to a positive or negative attitude towards computer use. The Computer Attitude Scale developed by Gressard and Loyd $^{[39]}$ divides attitude into four subscales: computer anxiety, confidence, usefulness and liking and they found that the perceived usefulness of computers can influence attitudes towards computers and the amount of confidence a teacher possesses in using computers may influence his or her implementation in schools. However, Russell and Bradley ${ }^{[40]}$ found that male teachers reported significantly greater confidence with computers than did females and recommended teacher professional development should take into account the particular needs of female teachers. On the other hand, Summers ${ }^{[1]}$ found that the lack of knowledge and experience in the computing area is one of the most common reasons for teachers' negative attitudes towards computers. Furthermore, computer anxiety is identified as a major cause of resistance to using computers ${ }^{[40]}$. Anxiety is an affective construct; it deals with emotion, which is subjective and relative in its meaning.

The etiology of computer anxiety has been reviewed from several theoretical stances. It may be a result of low self-efficacy, low expectations of outcome, or lack of reinforcement ${ }^{[42]}$. With the advent of computers into society has led to a specific concern about human emotional reaction toward it. Some individuals respond enthusiastically and quickly master the skill necessary for the effective application of computers. For others, the experience is very unpleasant and will exhibit anxiety when required to learn about or how to use computers ${ }^{[43]}$. Avoidance of computer interaction is the primary indicator of computer anxiety ${ }^{[44]}$. Howard ${ }^{[45]}$ identified three sources of computer anxiety: (a) lack of operational experience with computers, (b) inadequate knowledge about computers and (c) psychological makeup. He theorized that computer anxiety based on the lack of operational experience with computers is the easiest to treat, computer anxiety arising from knowledge-based origins is of intermediate difficult to treat and computer anxiety based on an individual's psychological makeup is the most difficult to treat.

Gardner et el. ${ }^{[46]}$ found that increased computer experience reduces computer anxiety in many teachers. Nevertheless, it may depend on the type and duration of computer experience ${ }^{[44]}$. In investigating the changes in teachers' attitudes towards computers, Yildirim ${ }^{[35]}$ found that teachers' attitudes (anxiety, confidence and liking) significantly improved after the computer literacy course. Meanwhile, Rovai and Childress ${ }^{[47}$ selected a number of predictor variables to explain and predict computer anxiety and attitude towards computer, on the basis of theoretical considerations. These include computer confidence, computer experience, computer knowledge, computer liking, perceived usefulness, locus of control and trait anxiety. They identified that the significant predictors of computer attitude and anxiety were related to psychological makeup of subjects, their computer knowledge and their use of computers.

Zhang and Espinoza ${ }^{[48]}$ found that attitudes towards the computer-in particular measures of comfort/anxiety and perceived usefulness-were significant predictors of the need for learning computing skills, which will in turn greatly affect the intention to use computers and the actual use of computers. From the literature, it is transparent that the successful use of computers in 
schools depends largely on the teachers' attitudes towards computers. Some teachers are often resistant to using computers in the classroom, so the development of teachers' positive attitudes towards computers is considered to be a key factor in fostering computer integration in schools ${ }^{[49]}$.

\section{PERCEIVED USEFULNESS AND PERCEIVED EASE OF USE}

Hu et al. ${ }^{[30]}$ described Perceived Usefulness (PU) as to the extent to which computer is considered by an individual to be useful, Whereas Perceived Ease Of Use (PEOU) is the degree to which an individual views his or her use of computer to be free of effort. There is widespread research in the IT community that provides evidence of the significant effect of PU on usage intention and the $\mathrm{AUC}^{[50-52]}$. On top of it, there was also extensive research that provides evidence of significant effect PEOU has on usage intention, whether affecting directly or not ${ }^{[29,50-52]}$. According to Davis ${ }^{[53]}$, PEOU and PU are important perceptions determining IT adoption. In a later study that expanded on the original technology acceptance model studies, Davis et al. ${ }^{[54]}$ explained the role of these beliefs, suggesting that user intention to adopt a new IT is affected by both extrinsic and intrinsic motivations.

According to Davis et al..$^{[54]}$, extrinsic motivation refers to the performance of an activity because it is perceived to be instrumental in achieving valued outcomes that are distinct from the activity itself. In contrast, intrinsic motivation refers to the performance of an activity for no apparent reinforcement other than the process of performing the activity $\mathrm{sec}^{-1}$. Davis et $a .^{[54]}$ classified enjoyment as a type of intrinsic motivation and $\mathrm{PU}$ as a type of extrinsic motivation, arguing that extrinsic motivation should have a stronger impact on IT adoption. The reason PU is such an important antecedent of IT adoption is that in many cases a new IT is adopted primarily because it is instrumental in achieving tasks that are not inherent in the use of IT itself. PU deals with user assessments of these aspects of a new $\mathrm{IT}^{[54]}$. Davis ${ }^{[53]}$ originally examined an e-mail system and a file-editor used at the time at IBM Canada and found that both PEOU and PU were significantly correlated with self-reported use of both systems. However, when the combined effect of PU and PEOU on self-reported use was examined using linear regression, only PU significantly affected use.

In the education field, teachers' perception on the usefulness of computer technology, understanding of this technology and feelings related with the perceived ease of use of the support structure associated with computers have been examined with the findings suggesting that teachers believe PU and PEOU are an integral part of the process of using computers ${ }^{[55]}$. Included in this finding are three subassertions and they are as follows: (a) most teachers in the study felt confident in their ability to use computer technology since they perceived it as useful for students, (b) teachers believe computer technology is an integral part of their classrooms and it should be easy to use and (c) teachers believe their classrooms need more computer technology and its user interface should be less sophisticated.

Computer self-efficacy: According to Zhao et al. ${ }^{[56]}$, it is not only the teacher's proficiency that play an important role in successful implementation of classroom technology innovations but that a teacher's efficacy of the enabling conditions to implement a specific technology was equally important. Selfefficacy is one of the motivational components under the self-schema category. As a performance-based measure of perceived capability, it differs conceptually and psychometrically from other constructs such as outcome expectations, self-concept, or locus of control $^{[57]}$. Bandura and Schunk ${ }^{[58]}$ defined self-efficacy as being concerned with judgments about how well one can organize and execute courses of action required to deal with prospective situations concerning many ambiguous, unpredictable and often stressful elements. In relation to this, it can be defined that teacher efficacy as a teacher's expectation that he or she will be able to bring about student learning. Bandura ${ }^{[31]}$ also proposed that self-efficacy beliefs play a distinct role in psychosocial behavior that will influence how people behave, their thought patterns and emotional reactions in various situations. It was identified that selfefficacious teachers participate more readily, work harder, persist longer and have fewer adverse emotional reactions when they encounter difficulties than do those who doubt their capabilities ${ }^{[59]}$.

There was quite a substantial amount of study that has been done investigating on the effects of selfefficacy on usage of computers and performance. Educators with high self-efficacy are more likely to try out new teaching ideas, particularly techniques that are difficult to implement and involve risks such as sharing control with students ${ }^{[60]}$. Besides, Pajaras and Kranzler $^{[61]}$ too found that ability and self-efficacy had strong direct effects on performance. Ability also had a strong direct effect on self-efficacy, which mediated the indirect effect of ability and level of performance. Zhao et al. ${ }^{[56]}$ adds that teachers who were highly reflective and confident about their teaching practice 
and goals were more likely to yield positive results. Moreover, teachers who viewed technology as a means to an end, rather than an end itself, were also more likely to yield positive results.

A number of studies too have been carried out that showed direct positive relationship between computer self-efficacy and usage of computer, particularly in the constructs of computer confidence and computer competence and how self-efficacy affects performance. The importance of confidence in explaining computer beliefs is largely due to its inclusion as an attitude subscale by Loyd and Gressard ${ }^{[62]}$. Hunt and Bohlin ${ }^{[63]}$ found that the confidence subscale of Loyd and Gressard $^{[62]}$ was predicted by computer use for recreation and experience in word processing, programming and databases. Similarly, Nash and Moroz $^{[64]}$ found that Loyd and Gressard's ${ }^{[62]}$ confidence subscale explained $32 \%$ of the variance in scores measuring intensity of computer usage. In addition, Zammit $^{[65]}$ not only found that non-users rated a lack of self-confidence among factors that hindered their use of computers but found a significant difference in selfconfidence between users and non-users. On top of it, Marcinkiewicz ${ }^{[6]}$ found that self-competence was not only significantly related to teachers' level of computer use but was the strongest predictor of levels of computer use for teachers. Similarly, McInerney et $a l .{ }^{[44]}$ found that self-competence was significantly related to lower levels of computer anxiety in educators and higher level of computer usage.

Job relevance: Previous studies have shown that job relevance has relatively influenced $\mathrm{AUC}^{[67,68]}$. The importance of job relevance or value as a predictive factor of actions and behavior owes its origins to motivation theory. In earlier models, value was conceived in terms of incentive value of pride or inhibitive value of shame that an individual attached to success or failure of tasks, respectively ${ }^{[6]}$. More recent models have conceptualized value in broader terms related to usefulness or relevance ${ }^{[70]}$. In terms of usefulness, value has been an important component in measuring computer attitudes ${ }^{[71]}$. Becker and Riel ${ }^{[67]}$ and Zhang and Espinoza ${ }^{[72]}$, for example, found that usefulness was significantly related to teachers' desire to learn computing skills as well as their confidence and comfort in working with a computer.

Research studies have also investigated value in terms of the general relevance of computers for teaching and students. Marcinkiewicz ${ }^{[6]}$ found that while relevance of computes for teaching was significantly related to teachers' self-competence in using a computer, it was not a significant predictor of their level of computer use. Marcinkiewic ${ }^{[66]}$ did find, however, that relevance was a significant predictor for teachers' level of computer use. Besides, in terms of imparting knowledge to the students by the teachers, Zammit ${ }^{[65]}$ found that the need for students to learn how to use technology was one of the important factors in facilitating computer use by teachers who used computers.

Expanding upon the concept of job relevance, Keller $^{[68]}$ operationalized value into three sub conditions: value for own needs, career and others. Using this model, Kellenberger ${ }^{[73]}$ found that the value of computers for teachers' own needs and career together were significantly related to their actual usage of the computers. In addition, Kellenberger ${ }^{[73]}$ found that the value of computers for teachers' own needs, career and to educate students were the best predictors of computer use under differential access to computer resources.

Subjective norm: Hu et al. ${ }^{[30]}$ mentioned that within a social system, an individual's technology acceptance decision and its usage may be influenced by opinions to varying degrees. Successful usage of computers in schools by teachers is very much associated with the teacher's awareness of the social dynamics of the school. By and large, schoolteachers appear to have strong psychological attachments to the school community and exhibit close bonds with their colleagues. Findings from various studies show that classroom teachers' readiness to use technology will increase with strong support systems that include peers, communities, parents, business leaders and administrators. Taylor ${ }^{[74]}$ states that influence of superiors and peers are antecedents to the subjective norm.

Technology does not exist in a vacuum and neither do educators. School systems are cultures with many different factors contributing toward teachers' growth and development ${ }^{[11]}$. The norms of administrators and colleagues can positively or negatively influence the attitudes and behavior of individual educators. Research indicates that administrators are the key to successful implementation of technology in classroom and adoption of technology innovations by teachers in schools $^{[75]}$. Principals who are role models understand the relevance of computer technology in schools and thus enhance the use of technology in classrooms. They provide the added support and guidance teachers are looking for ${ }^{[75]}$.

Besides, school administrators who openly support their teachers through quality staff development IT 
programs will have teachers more willing to take risks and consider alternate pedagogical venues ${ }^{[12]}$. Moreover, teachers who were socially aware, know where to gain support and resources and be more sensitive to the needs and priorities of their colleagues and are willing to explore further to enhance the usage of computer in classrooms ${ }^{[76]}$. On top of it, other factors that may contribute to the attachments or bonds, such as the non-profit nature of schools, lack of competition among peers, long-term career pursuit and the relatively closed-loop community ${ }^{[30]}$ may motivate a teacher to use or reject a technology in order to comply with important referents' opinions.

Computer compatibility: There is little consensus in the literature as to what constitutes computer compatibility. The first definitions to appear in the literature identified computer compatibility as an understanding of hardware and software. The teacher is expected to know the internal and external workings of the computer ${ }^{[77]}$. Educators were expected to be familiar with computer programming, languages and demonstrate competence writing, debugging and testing programs ${ }^{[78]}$. Besides, educators were also expected to have competencies such as (a) evaluating and matching appropriate software to a learner's skills and abilities, (b) helping students use the computer as a personal productivity tool, (c) assessing individual needs and (d) integrating computer technology into multiple environments $^{[79]}$. Thus, computer compatibility has been defined as knowledge of computer characteristics, capabilities and applications, as well as the user's ability to implement this knowledge productively.

Lately, as computers became established in the classroom as teaching tools, educators more clearly understood the need for teachers to be able to confidently use the hardware and evaluate a range of software packages that is relevant to the curriculum ${ }^{[34]}$. Thus, computer compatibility as defined by $\mathrm{Hu}$ et al..$^{[30]}$ is teacher's acceptance of computer being well-suited with their working life styles and consistent with their existing values and able to satisfy their personal needs. In relation to this, in the computer system, its' hardware and software compatibility may affect a teacher's decision to use or reject a technology. According to Gilbert's ${ }^{[80]}$ Behavior Model, technology (hardware) and resources (software) are critical to encouraging the adoption of instructional technology although the teacher may have control over some environmental factors

There were many studies that showed the influence of computer compatibility with the actual use of computers $^{[30,34,81]}$. Hu et al. ${ }^{[30]}$ identified that being compatible with computer consistently affects a teacher's usage of computers. Besides, in Morton's ${ }^{[81]}$ study, a marked significant difference was also found on the usage of computers between teachers with varying computer compatibility. He found teachers with low computer compatibility engaged in more traditional pedagogical practices and found it more difficult to assimilate computers into their teaching style. On the other hand, teachers with high computer compatibility integrated computers into their pedagogical practices readily.

\section{CONCLUSION}

It is transparent that teachers' usage of computer is determined by the frequency and amount of time a teacher spends utilizing the computer and this could be the interaction with the hardware as well as the software or the programs for the purpose of teaching and learning, administration and personal needs. The computer has now become a part and parcel of a teacher's life just as much as a student has become a part of the teacher. The computer plays a vital role in enabling the teacher to go through the life as a successful teacher by the many uses it caters for the teacher ${ }^{[4]}$.

The technology acceptance model could be used without doubt by future researchers as primary theoretical understanding on the usage of computer among teachers. The technology acceptance model is a well-known model for predicting and explaining individual behavior on the usage of information technology ${ }^{[23]}$. Moreover the technology acceptance model is a parsimonious, theoretically and empirically justified model that is intended to explain the usage of information system $^{[17]}$ and has a high degree of reliability and validity. It is recommended that future researchers expand the original technology acceptance model ${ }^{[19]}$ by integrating the extended technology acceptance $\operatorname{model}^{[30]}$, the innovation diffusion theory ${ }^{[32]}$ and the social-cognitive theory. In this endeavor, future studies should be able to develop a model that can provide useful information on AUC among teachers, while at the same time maintain the technology acceptance model's theoretical and psychometric rigor.

After a thorough search on all the available resources, a small amount of studies pertaining to computer usage among teachers had been reported using the extended technology acceptance model as the foundation for theoretical framework. Thus, it is hoped that future studies would contribute to the existing literature by examining different variables that might 
have been neglected previously. Consequently, this would add to the body of knowledge pertaining to AUC among teachers.

School teachers would gain much benefit from future studies. The technology acceptance constructs would reveal factors that explain teachers' usage of computers in schools. For instance, the study will show the kind of attitude teachers possess towards the usage of computer. Besides, the findings would also reveal precisely the main contributing factors that influence teachers' computer usage. Hence, it is believed that future findings would add new perspective on understanding the complexities associated with computer and learning among teachers. Future studies should be able to picture whether teachers are ready to embrace computer and be more comfortable to integrate computer technology in the process of teaching and learning. More importantly, it would show whether the digital investment by the government had produced the expected results.

\section{REFERENCES}

1. Sherry, L., S. Bilig, D. Jesse and D.W. Acosta, 2001. New insights on technology adoption in schools. T. H. E. J., 27: 42-46.

2. Loveless, T., 1996. Why aren't computers used more in schools? Educat. Policy, 10: 448-467.

3. Gibbons, A.S. and P.G. Fairweather, 1998. Computer-Based Instruction: Design and Development. 1st Edn. Educational Technology Publications, New Jersey.

4. Cuban, L., 2001. Oversold and Underused: Computers in the Classroom. 1st Edn. Harvard University Press, Cambridge MA.

5. Brunner, T., T. Cornelia and T. William, 1999. The New Media Literacy Handbook. 1st Edn. Anchor, New York.

6. Adams, D.A., Nelson, R.R., Todd, P.A. 1992. Perceived usefulness, ease of use, and usage of information technology: a replication. MIS $Q$., 16:227-47.

7. George, A.S., K. McEwin and J.M. Jenkins, 2000. The Exemplary High School. 1st Edn. Harcourt, New York.

8. Kellenberger, D.W. and S. Hendricks, 2000. Predicting teachers' computer use for own needs, teaching and student learning. J. Educat. Comput. Res., 16: 53-64.

9. Provenzo, E. (2002). The Internet and the world wide web for teachers . 2nd Edn. Allyn and Bacon: Boston

10. Heppell, S. 1993. Teacher Education, Learning and the Information Generation: the progression and evolution of educational computing against a background of change. J. of Information Technol. for Teacher Edu., 2:229-237
11. Stefl-Mabry, J., 1999. Professional staff development: Lessons learned from current usability studies. J. Inform. Technol. Impact., 1: 81-104.

12. Dillon, A. and M.G. Morris, 1996. User acceptance of information technology: Theories and models. Ann. Rev. Inform. Sci. Technol., 31: 3-32.

13. Kukafka, R., S.B. Johnson, A. Linfante and J.P. Allegrante, 2003. Grounding a new information technology implementation framework in behavioral science: A systematic analysis of the literature on IT use. J. Biomed. Inform., 36: 218-227.

14. Gery, G., 1997. Granting three wishes through performance-centered design. Commun. ACE, 40: 54-59.

15. Mathieson, K., 2001. Predicting user intentions: Comparing the technology acceptance model with the theory of planned behavior. Inform. Syst. Res., 2: 173-191.

16. Ajzen. I. and T.J. Madden, 1986. Prediction of goal-directed behavior: Attitudes, intentions and perceived behavioral control. J. Soc. Psychol., 22: 453-474.

17. Heijden, H., 2003. Factors influencing the usage of websites: The case of a generic portal in The Netherlands. Inform. Manage., 40: 541-549.

18. Davis, F.D. 1989. Perceived usefulness, perceived ease of use, and user acceptance of information technology. MIS Q, 13:319-39.

19. Davis, F.D., R.P. Bagozzi and P.R. Warshaw, 1989. User acceptance of computer technology: A comparison of two theoretical models. Manage. Sci., 35: 982-1003.

20. Taylor, S. and P. Todd, 1995. Assessing IT usage: The role of prior experience. MIS Q., 19:561-570.

21. Chau, P.Y.K. and P.J. Hu, 2002. Information technology acceptance by individual professionals: A model comparison approach. Decision Sci., 32: 699-719.

22. Igbaria, M., N. Zinatelli, P. Cragg and A. Cavaye, 1997. Personal computing acceptance factors in small firms: A structural equation model. MIS Q., 21: 279-302.

23. Shih, H.P., 2004. Extended technology acceptance model of internet utilization behavior. Inform. Manage., 41: 719-729.

24. Ong, C.S., J.Y. Lai and Y.S. Wang, 2006. Factors affecting acceptance of asynchronous e-learning systems in high-tech companies. Inform. Manage., 41: 795-804.

25. Trombley, K.B. and D. Lee, 2006. Web based learning: who is using it and why, who is not and why not? J. Educat. Media, 27: 137-146.

26. Lee, V.E., 1997. Effects of high school restructuring and size on early gains in achievement and engagement. Sociol. Educat., 68: 241-70. 
27. Luarn, P. and H. Lin, 2004. Toward an understanding of the behavioral intention to use mobile banking. Comput. Hum. Behav., 30: 1-19.

28. Malhotra, Y. \& Galletta, D.F. 1999. Extending the Technology Acceptance Model to Account for Social Influence: Theoretical bases and empirical validation, in the Proceedings of the Hawaii International Conference on System Sciences (HICSS 32) (Adoption and Diffusion of Collaborative Systems and Technology Minitrack) (pp.6-19), Maui, HI, January 5-8.

29. Venkatesh, V. and F.D. Davis, 1996. A theoretical extension of the technology acceptance model: Four longitudinal field studies. Manage. Sci., 46: 186-204.

30. Hu, P.J., T.H.K. Clark and W.W. Ma, 2003. Examining technology acceptance by school teachers: A longitudinal study. Inform. Manage., 41: 227-241.

31. Bandura, A., 1986. Social Foundations of Thought and Action. 1st Edn. Prentice Hall, Englewood Cliffs, New Jersey.

32. Rogers, E.M., 1995. Diffusion of Innovation. 4th Edn. Free Press, New York.

33. Mumtaz, S., 2000. Factors affecting teachers' use of information and communications technology: A review of the literature. J. Inform. Technol. Teacher Educat., 9: 319-341.

34. Dusick, D.M., 1998. What social cognitive factors influence faculty members' use of computers for teaching? A literature review. J. Res. Comput. Educat., 31: 123-140.

35. Yildirim, S., 2000. Effects of an educational computing course on preservice and inservice teachers: A discussion and analysis of attitudes and use. J. Res. Comput. Educat., 32: 479-495.

36. Woodrow, J.E., 1992. The influence of programming training on the computer literacy and attitudes of preservice teachers. J. Res. Comput. Educat., 25: 200-218.

37. Becker, H.J., 1993. How exemplary computerusing teachers differ from other teachers: Implications for realizing the potential of computers in schools. J. Res. Comput. Educat., 26: 291-321.

38. Kontos, G., 1997. Global village classroom. The changing roles of teachers and students through technology. TechTrends, 43: 17-22.

39. Gressard, C.P. and B.H. Loyd, 1985. Age and staff development experience with computers as factors affecting teachers' attitudes toward computers. School Sci. Math., 85: 203-209.
40. Russell, G. and G. Bradley, 1997. Teachers' computer anxiety: implications for professional development. Educat. Inform. Technol., 2: 17-30.

41. Summers, M., 1990. New student teachers and computers: An investigation of experience and feelings. Educat. Rev., 42: 261-271.

42. Meier, S., 1985. Computer aversion. Comput. Hum. Behav., 12: 327-334.

43. Marcoulides, G.A., 1988. The relationship between compute anxiety and computer achievement. J. Educat. Comput. Res., 4: 733-739.

44. McInerney, V., D.M. McInerney an K.E. Sinclair, 1994. Student teachers, computer anxiety and computer experience. J. Educat. Comput. Res., 11:27-50.

45. Howard, G.S., 1986. Computer Anxiety and the Use of Microcomputers in Management. 1st Edn. UMI Research Press, Ann Arbor, MI.

46. Gardner, D.G., R. Discenza and R.L. Dukes, 1993. The measurement of computer attitudes: An empirical comparison of available scales. J. Educat. Comput. Res., 9: 487-507.

47. Rovai, A.P. and M.D. Childress, 2003. Explaining and predicting resistance to computer anxiety reduction among teacher education students. J. Res. Technol. Educat., 35: 226-235.

48. Zhang, Y. and S. Espinoza, 1997. Affiliations of computer self-efficacy an attitudes with need for learning computer skills. J. Comput. Res., 17: 371-383.

49. Yuen, H.K., N. Law and H. Chan, 1999. Improving IT Training for Serving Teachers through Evaluation. In: Advanced Research in Computers and Communications in Education, Vol. 2, Cumming, G., T. Okamotoa and L. Gomez (Eds.). IOS Press, Amsterdam, pp: 441-448.

50. Venkatesh, V. and M.G. Morris, 2000. Why do not men ever stop to ask for directions? Gender, social influence and their role in technology acceptance and usage behavior. MIS Q., 24: 115-139.

51. Agarwal, R. and J. Prasad, 1999. Are individual differences germane to the acceptance of new information technologies? Decision Sci., 30: 361-391.

52. Hu, P.J., P.Y.K. Chau, O.R.L. Sheng and K.Y. Tam, 1999. Examining the technology acceptance model using physician acceptance of telemedicine technology. J. Manage. Inform. Syst., 16: 91-112.

53. Davis, F.D., 1989. Perceived usefulness, perceived ease of use and user acceptance of information technology. MIS Q., 13: 318-339. 
54. Davis, F.D., R.P. Bagozzi and P.R. Warshaw, 1992. Extrinsic and intrinsic motivation to use computers in the workplace. J. Applied Soc. Psychol., 22: 1111-1132.

55. Clark, K., 2000. Urban middle school teachers' use of instructional technology. Res. Comput. Educat., 33: 178-196.

56. Zhao, Y., K. Pugh, S. Sheldon and J. Byers, 2002. Conditions for classroom technology innovations. Teachers Coll. Rec., 104: 482-515.

57. Zimmerman, B.J., 2000. Self-efficacy: An essential motive to learn. Contemp. Educat. Psychol., 25: 82-91.

58. Bandura, A. and D.H. Schunk, 1981. Cultivating competence, self-efficacy and intrinsic interest through proximal self-motivation. J. Personal. Soc. Psychol., 41: 568-598.

59. Bandura, A., 1997. Self-Efficacy: The Exercise of Control. 1st Edn. Freeman, New York.

60. Hani, J., C. Czerniak and A. Lumpe, 1996. Teacher beliefs and intentions regarding the implementation of science education reform strands. J. Res. Sci. Teach., 33: 971-993.

61. Pajaras, F. and J. Kranzler, 1995. Self-efficacy beliefs and general mental ability in mathematical problem-solving. Contemp. Educat. Psychol., 20: 426-443.

62. Loyd, B.H. and C. Gressard, 1986. Reliability and factorial validity of computer attitude scales. Educat. Psychol. Measure., 44: 501-505

63. Hunt, N.P. and R.M. Bohlin, 1993. Teacher education students' attitudes toward using computers. J. Res. Comput. Educat., 25: 487-497.

64. Nash, J.B. and P.A. Moroz, 1997. An Examination of the factor structures of the computer attitude scale. J. Educat. Comput. Res., 17: 341-356.

65. Zammit, S.A., 1992. Factors facilitating or hindering the use of computers in schools. Educat. Res., 34: 57-66.

66. Marcinkiewicz, H.R., 1995. Differences in computer use of practicing versus preservice teachers. J. Res. Comput. Educat., 27: 184-197.

67. Becker, H.J. and Ravitz, J.L. 1999. The influence of computer and Internet use on teachers' pedagogical practices and perceptions. J. of Research on Comp. in Edu., 31: 356-384.

68. Keller, J. M. .1983. Motivational design of instruction. In C. M. Reigeluth (Ed.), Instructionaldesign theories and models: An overview of their current status (pp. 383-434).Lawrence Erlbaum : Hillsdale, New Jersey

69. Atkinson, J.W., 1964. An Introduction to Motivation. 1st. Edn. Van Nostrand, Princeton, New Jersey.
70. Eccles, J. 1983. Expectancies, values, and academic behaviors. In J. T. Spence (Ed.), Achievement and achievement motives: Psychological and sociological approaches (pp 75146). San Francisco: Freeman.

71. Delcourt, M.A. and M.B. Kinzie, 2002. Computer technologies in teacher education: The measurement of attitudes and self-efficacy. J. Res. Develop. Educat., 27: 35-41.

72. Zhang, Y. and S. Espinoza, 1998. Relationships among computer self-efficacy, attitudes towards computers and desirability of learning computing skills. J. Res. Comput. Educat., 30: 420-431.

73. Kellenberger, D.W., 2000. Preservice teachers' perceived computer self-efficacy based on achievement and value beliefs within a motivational framework. J. Res. Comput. Educat., 29: 124-140.

74. Taylor, S., 1996. Understanding information technology usage: A test of competing models. Inform. Syst. Res., 6: 144-176.

75. Hoffman, B., 2001. Integrating technology into schools. Educat. Digest., 62: 51-55.

76. Guha, S., 2003. Are we all technically prepared? Teachers' perspective on the causes of comfort or discomfort in using computers at elementary grade teaching. Inform. Technol. Childhood Educat. Ann., 1:317-349.

77. Higdon, J., 1995. The evolution of computer literacy for preservice teachers. Educat. Technol., 42: 59-77.

78. Beigel, A.R., 1996. Developing computer competencies among special needs educators. Learn. Lead. Technol., 23: 69-71.

79. Willis, J. and D. Mehligner, 1996. Information Technology and Teacher Education. In: Handbook of Research on Teacher Education, Sikula, J., T. Buttery and E. Guyton (Eds.). Macmillan, New York.

80. Gilbert, W.M., 1996. Resistance to computers and computer experience: A new look at an old relationship. J. Educat. Comput. Res., 14: 261-271.

81. Morton, A., 2002. Factors Affecting Integration of Computers in Western Sydney Secondary Schools. In: Learning Technologies: Prospects and Pathways, Hedberg, J.G., J.R. Steele and S. McNamara (Eds.). AJET Publications, Canberra, Australia, (ERIC No. ED 396 737), pp: 107-114. 